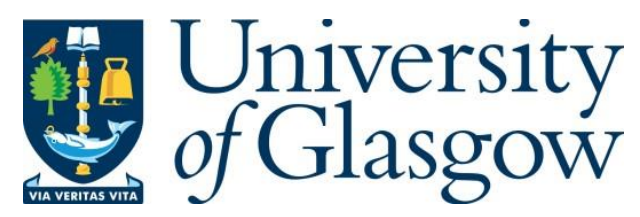

Kotzee, B., Carter, J. A. and Siegel, H. (2019) Educating for intellectual virtue: a critique from action guidance. Episteme, (doi:10.1017/epi.2019.10)

There may be differences between this version and the published version. You are advised to consult the publisher's version if you wish to cite from it.

http://eprints.gla.ac.uk/179316/

Deposited on: 5 February 2019

Enlighten - Research publications by members of the University of Glasgow http://eprints.gla.ac.uk 
Forthcoming in Episteme

\title{
Educating for Intellectual Virtue: a critique from action guidance
}

\author{
Ben Kotzee (Birmingham), J. Adam Carter (Glasgow) \& Harvey Siegel (Miami)
}

\begin{abstract}
Virtue epistemology is among the dominant influences in mainstream epistemology today. An important commitment of one strand of virtue epistemology - responsibilist virtue epistemology (e.g., Montmarquet 1993; Zagzebski 1996; Battaly 2006; Baehr 2011) - is that it must provide regulative normative guidance for good thinking. Recently, a number of virtue epistemologists (most notably Baehr, 2013) have held that virtue epistemology not only can provide regulative normative guidance, but moreover that we should reconceive the primary epistemic aim of all education as the inculcation of the intellectual virtues. Baehr's picture contrasts with another well-known position that the primary aim of education is the promotion of critical thinking (Scheffler 1989; Siegel 1988; 1997; 2017). In this paper - that we hold makes a contribution to both philosophy of education and epistemology and, a fortiori, epistemology of education - we challenge this picture. We outline three criteria that any putative aim of education must meet and hold that it is the aim of critical thinking, rather than the aim of instilling intellectual virtue, that best meets these criteria. On this basis, we propose a new challenge for intellectual virtue epistemology, next to the well-known empiricallydriven 'situationist challenge'. What we call the 'pedagogical challenge' maintains that the intellectual virtues approach does not have available a suitably effective pedagogy to qualify the acquisition of intellectual virtue as the primary aim of education. This is because the pedagogic model of the intellectual virtues approach (borrowed largely from exemplarist thinking) is not properly actionguiding. Instead, we hold that, without much further development in virtue-based theory, logic and critical thinking must still play the primary role in the epistemology of education.
\end{abstract}

\section{Introduction}

In recent years, education has received renewed interest in epistemology. This is especially so in the field of virtue epistemology. According to one important tradition in virtue epistemology - the responsibilist approach, associated with, for instance, Code (1987), Montmarquet (1993), Zagzebski (1996), Battaly (2015) and Baehr (2011) - the question of how one learns to be virtuous is tied up with what it means to be virtuous. Furthermore, because responsibilist virtue epistemology is normative, it aims to provide guidance or instruction regarding how to think. In this vein, a number of contemporary philosophers working in the virtue-epistemology tradition (e.g., Baehr 2013; Battaly 
2006; Pritchard 2013; Kidd 2016' Tanesini 2016) have advanced the view that education should aim at the acquisition and development of intellectual character virtues, and have suggested ways in which education can fulfil that aim $^{2}$. Education is both a field that virtue epistemologists study and one that they aim to influence.

The matter of what the epistemic aim of education is and how to meet that aim has long been a central research question in the philosophy of education ${ }^{3}$. In this paper we acknowledge that while the increasingly popular idea that the primary aim of education is the development of intellectual virtue has much promise, it also has some hitherto unacknowledged shortcomings. In particular, we argue that the intellectual virtue approach does not have available a suitably effective pedagogy to help teach young people to develop better thinking skills, which, it is claimed, is a necessary ingredient of possession of an intellectual virtue (Baehr 2011, 2013a, 2016) ${ }^{4}$. In this respect, we maintain that (and contra Baehr 2013) the critical thinking approach (e.g., Scheffler 1989; Siegel 1988; 1997; 2017) can lay claim to several key advantages over the intellectual virtue approach. We argue - as two cautious supporters and one gentle critic of the intellectual virtue approach - that the latter is not yet, without substantial further development, in a position to rival the former.

The issue is important practically because what education is conceived as aiming at - viz., what the educational ideal is - will determine how the school curriculum and assessment methods should be organised, and even more generally, the best physical, social and cultural environment for schooling ${ }^{5}$. Moreover, it is important epistemically, because the question of whether education primarily aims at intellectual virtue or at critical thinking raises an important challenge (the 'pedagogical challenge') regarding the amount of normative advice that follows from virtue-based theories in

${ }^{1}$ Kidd's (2016) preferred term is 'edificationism'.

2 These authors have, in different places, embraced version of the intellectual virtue approach, some to differing strengths (and not all to the same extent as Baehr 2013).

${ }^{3}$ See Carter \& Kotzee (2015), Siegel (2004; 2013) and Watson (2016) for an overview of some of these positions. Note that thinking of the critical thinking and intellectual virtue views as rivals with respect to educational primacy is perfectly compatible (as it should be) with acknowledging that intellectual virtues and critical thinking skills can, and perhaps often do, mutually enhance one another. A flexible and open-minded agent, for instance, might be more disposed to exercise critical thinking skills, while the cultivation of their skills might, in turn, be aided by the possession of intellectual virtues. Thanks to an anonymous referee for highlighting this point.

${ }^{4}$ This is not to say that proponents of the intellectual virtue approach have not offered pedagogical proposals. Rather, we will be critiquing some of the leading such proposals and show them to be lacking in important respects.

${ }^{5}$ For helpful discussion of how neglect of such environments can have epistemically deleterious effects, see Kidd (2018). 
epistemology generally. More than just an applied question about schools, teachers and teaching, the question whether education should aim principally at intellectual virtue or critical thinking is fullstrength epistemology.

\section{The Intellectual Virtue Approach}

According to what we'll call the intellectual virtue approach - championed most forcefully by Baehr (2013) - the primary aim or goal of education is to foster intellectual virtues, such as curiosity, open-mindedness, intellectual courage, and intellectual honesty. ${ }^{6}$ Note that this is not the claim that promoting IVs is the only aim, or the only worthwhile value in education. More subtly, the core idea is that the IV aim is more fundamental in comparison with other competing educational aims, such as critical thinking; when such aims conflict and force teachers to make choices over what and how they teach, the intellectual virtue aim should be prioritised. In this section, we will articulate and clarify some of the key contours of the intellectual virtue approach to education, which has - largely due to an influx of work at the intersection of virtue epistemology and the philosophy of education - been gaining traction over the past decade or so. ${ }^{7}$

First, though, some key terms need to be sharpened in order to evaluate the core thesis that the proponent of the intellectual virtue approach is putting forward. Notice that the very suggestion that the primary aim or goal of education is to foster intellectual virtues presupposes a more basic idea: that education has a primary aim or goal. But this more basic claim itself requires some qualification. What, precisely, is one committed to in virtue of maintaining that, for any goal, $X-$ be it intellectual virtue, knowledge, critical thinking, etc. $-X$ is the 'primary aim' of education? ${ }^{8}$

\footnotetext{
6 (Baehr 2013, 248). We note that the aims of education considered here are primarily epistemic aims. Their relation to and priority over other aims, e.g., moral and social/political aims, deserves further discussion than we can give them here.

7 See, in particular, the essays in Baehr (2016). For an overview of recent work on the epistemic aims of education, see Kotzee (2013), Carter \& Kotzee (2015) and Siegel (2018).

8 'Aims' has (at least) three notably different senses: constitutive, teleological and intentional. Consider, for example, the claim that truth is the primary aim of belief. This claim is often glossed as the thesis that truth is the constitutive aim of belief, a claim that involves a commitment to thinking that part of what it is for something to be a belief is that it is governed by the truth aim-viz., it is correct if and only if true (e.g., Shah 2003; Shah and Velleman 2005; Wedgwood 2002). This strong constitutive claim is entailed neither by the intentional aim claim that believers aim at truth, nor by the teleological aim claim that the purpose or characteristic function of believing is to attain truth.
} 
According to Israel Scheffler (e.g., 1989, pp. 1, 62), the thesis that critical thinking is the primary aim or goal of education' commits one to regarding critical thinking as: (i) 'of first importance in the conception and organisation of educational activities'; and (ii) the educational value that should be maximized by making 'as pervasive as possible the free and critical quest for reasons'; and as, Bailin and Siegel $(2003,189)$ put it, (iii) that no other aims or ideals 'outrank the primary obligation of educational institutions and efforts to foster critical thinking'. More than just a point about critical thinking as an important aim of education, the point is a general one about what it means to say that some aim is the primary aim of education. For example, the proposal that some aim A is the (primary) aim of education implies that trying to secure $\mathrm{A}$ is what one principally (and not merely coincidentally) drives at in organising educational activities (like writing curricula, designing teaching sessions, setting exams, etc.) and that educational activities should be organised so as to maximise A. Furthermore, claims about the aim of education are usually made in the context of having to adjudicate between rival aims when organising educational activities; accordingly, the claim that something $\mathrm{A}$ is the primary aim of education carries the implication that, when it comes to a decision about which out of the number of possible educational values to promote, the maximisation of A trumps all other considerations. In short, this kind of primacy claim carries with it (at least) three commitments concerning (i) organisation; (ii) value maximisation; and (iii) obligation ranking.

Organisation claim: Educational activities should be organised to achieve $\mathrm{A}^{10}$;

Value maximisation claim: A is the primary educational value, in comparison with other competing educational values, that should be maximized;

Obligation ranking claim: No other education aim outranks the primary obligation of education efforts and institutions to foster the development of A.

Following this scheme, the intellectual virtue approach should be read as committed to a parallel set of claims vis-à-vis intellectual virtue:

\footnotetext{
9 See, for example, Scheffler 1989; Siegel 1988, 1997, 2017. Another rival approach, which articulates the primary aim of education in terms of knowledge, is defended by (among others) Goldman (1999) and Adler (2003). Yet another, advanced by Catherine Z. Elgin, articulates it in terms of understanding (Elgin 1999).

${ }^{10}$ Baehr (2013; forthcoming), for example, maintains that the development of intellectual virtues should be conceived of as an educational ideal, and he views the intellectual virtue ideal to be superior to what he takes to be its principal rival -viz., the critical thinking ideal. For related arguments, see especially Baehr (2013, 249-55) and Baehr (forthcoming). For related arguments, see Baehr (2013, 249-55). Note that some more general supporters of intellectual virtue views in education have focused not on the promotion of intellectual virtues, as such, but on the promotion of specific intellectual virtues in the classroom. A notable example here is Lani Watson's (2015) work on inquisitiveness and the role of questioning in the classroom as a way of facilitating this goal.
} 
Organisation claim: Educational activities should be organised to promote intellectual virtue;

$V$ alue maximisation claim: Intellectual virtue is the primary educational value that should be maximized;

Obligation ranking claim: No other education aim (including critical thinking, knowledge, etc.) outranks the primary obligation of education efforts and institutions to foster the development of intellectual virtue.

The position is strong, but not unduly strong. The debate concerning the epistemic aim of education is a long-standing one (e.g., Siegel 2017; Marples 1999) and the heat in the debate is due not to conceptual differences about the concept of education, but due to normative disputes about how education should be carried out. Anyone claiming that A is the primary epistemic aim of education is thereby holding that education should be organised to promote aim A to a greater extent than some other aim, whenever and wherever these aims come apart ${ }^{11}$ - a claim, to be clear, that is entirely compatible with promoting other educational aims. (For example, often times, promoting other educational aims will also promote intellectual virtue, and vice versa).

A second component of the intellectual virtue approach that calls for elucidation is the very concept of an 'intellectual virtue'. Responsibilist character traits such as curiosity, open-mindedness, intellectual courage, and intellectual honesty are all paradigmatic intellectual virtues. However, the term 'intellectual virtue' also has a very different and influential meaning, at least, within the virtue reliabilist tradition advanced most notably by Ernest Sosa (2009; 2010; 2015) and John Greco (2003;

11 Granted, when it comes to intellectual virtue in particular, a number of prominent virtue epistemologists (e.g. Kvanvig 2003; Riggs 2003) are pluralists about epistemic goods: they hold that there is not only one epistemic good (say truth or knowledge), but multiple epistemic goods (like truth and knowledge, but also like understanding, wisdom, elegance, novelty, practicality and so-on) to pursue in our epistemic lives, none of which is more important than any other. Is it not possible that the advocate of intellectual virtue as an aim of education could be holding that - that fostering intellectual virtue is only one aim of education amongst many equally deserving aims (like inculcating knowledge, understanding, wisdom, etc.)? The advocate of intellectual virtue as the primary aim of education should not be read as holding merely that. For one thing, if educational aims were really so numerous, it would be easy to show that intellectual virtue is an aim of education. For another, they would not have to deny (e.g., as Baehr 2013 does) that something like critical thinking is the aim of education; it would be more sensible to strike a compromise to the effect that both intellectual virtue and critical thinking are educational aims. The dispute about what the aim of education is only makes sense if one aim is more important than another and can outrank another aim when it comes to allocation of scarce educational resources.. 
2010; 2012). On the Sosa/Greco model, intellectual virtues are best understood as reliable faculties such as memory, eyesight, introspection and the like ${ }^{12}$.

Importantly, proponents of the intellectual virtue approach in education (e.g., Baehr 2013; Battaly 2006; Pritchard 2013; Kidd 2016; Tanesini 2016; Watson 2015) have the former, rather than the latter, kind of intellectual virtue in mind. ${ }^{13}$ This is of course not to say that the intellectual virtue approach does not value the cultivation of reliable faculties; rather, the idea is that to the extent that reliable faculties should be promoted and fostered, this is to be explained in terms of the primary educational goal of fostering intellectual character virtues, and not the other way around.

According to Jason Baehr (2013) each individual virtue also has its own characteristic activity or psychology - as he puts it, an 'activity or psychology that is rooted in an underlying 'love' of epistemic goods' (2013, p. 249). He offers the following template definition:

Intellectual Virtue: for any intellectual virtue $V$, a subject $S$ possesses $V$ only if $S$ is:

(a) disposed to manifest a certain activity or psychology characteristic of $V$

(b) out of a love of epistemic goods $(2013,249)$.

Thus, on this model, an individual is open-minded only if she is disposed to manifest the kind of psychology characteristic of open-mindedness (e.g., is disposed to consider alternative standpoints) out of a love for epistemic goods (e.g., arriving at an accurate grasp of the matter at hand). ${ }^{14}$

Putting this all together, then, the intellectual virtue approach should be read as maintaining that the fostering and development of intellectual virtues, with the kind of psychological and motivational structure just articulated, constitutes the primary aim of education ${ }^{15}$. And this normative part of the claim implies (at least) that (i) educational activities and learning environments should be organised around the fostering of these kinds of states (organisation claim); (ii) which are the primary

\footnotetext{
12 Cf., Sosa (2017, pp. 140-156) for further discussion on this distinction, in particular in connection with the role of trait as opposed to faculty virtues in the project of analyzing knowledge.

13 See Greco and Turri (2015) and Battaly (2008) for some helpful overviews of this distinction - viz., between what is called virtue responsibilism and virtue reliabilism. For some proponents of the intellectual virtue approach in the philosophy of education whose context is not the virtue epistemology tradition, see for example, Kilby (2004), Bevan (2009) and Macallister (2012).

14 (Baehr 2013, 249). For a critique of Baehr's more detailed account of open-mindedness, as defended in Baehr (2011), see Carter \& Kotzee (2015). For a more general critique of Baehr's case for the superiority of the intellectual virtue aim to the critical thinking aim, see Siegel (2016).

15 Note that it is possible for a proponent of the intellectual virtue view to go further, and to maintain that intellectually virtuous individuals of the sort edified through a good education may be instrumentally valuable relative to further goods. Compare: Zagzebski (1996) views the intellectual virtues as a subset of a wider class of virtues that aim at human flourishing.
} 
educational value that educators should try to maximize (value maximization claim); and (iii) that no other education aim outranks the educational obligation to foster states with these kinds of profiles (obligation ranking claim).

Most contemporary defences of the intellectual virtue approach have attempted to vindicate this position on philosophical/axiological grounds, specifically, by appealing to the epistemic value of fostering intellectual virtues and on this basis defending their value in an educational setting. ${ }^{16}$ However, a vindication of the approach requires more than just a philosophical/axiological defence. The view must also be empirically as well as pedagogically defensible.

The primary empirical challenge to the intellectual virtue approach is the epistemic situationist challenge, which has been advanced in recent work by Mark Alfano (e.g., 2012; 2013) and Lauren Olin and John Doris (2014). These authors argue, on the basis of empirical work in moral psychology, that the postulation of cross-situationally stable character traits - e.g., intellectual character virtues and vices - in the service of explaining good and bad thinking is empirically undermined by the extent to which seemingly irrelevant situational-specific factors, including ones of which the subject may be consciously unaware, seem to be doing much of the relevant explanatory work. ${ }^{17}$ If the intellectual virtue approach is to be successful, it must satisfactorily respond to this empirical challenge. It is beyond our present aim to evaluate the IV approach on this point (although, a notable defence against this challenge is presented by Sosa 2017, Ch. 11).

Instead, we want to highlight a new challenge to intellectual virtues thinking. While this challenge is a general one, it surfaces particularly clearly in the field of education and we, therefore, explain it in the context of education. The 'pedagogical challenge' is that even if the intellectual virtue approach can be vindicated on philosophical/axiological grounds as well as (contra the epistemic situationist critique) on empirical grounds, there remains the question of whether intellectual virtue can be taught successfully. More precisely: even if the intellectual virtue approach is empirically

\footnotetext{
16 See, for example, Baehr (2013, 249-55) for three recent arguments to this end. See also Pritchard (2013) and Carter \& Kotzee (2015) for some achievement-oriented defences of this claim.

17 As John Turri $(2015$, \&2) captures some of these features: 'We're less likely to recognize someone’s face after working on difficult crossword puzzles than reading; we overestimate distances and upward angles when tired or carrying heavy equipment; we're worse at judging distances in hallways than in a field; we're more likely to accept a written claim as true when it's easy to read; we're more likely to judge someone credible who speaks quickly; we're more likely to think that easy to pronounce stocks will outperform difficult to pronounce ones. Add to these the more familiar biases and foibles with names such as the availability bias, the confirmation bias, the anchoring bias, the false consensus effect, base rate neglect, the conjunction fallacy enumerated in textbooks on judgment and decision making'. While the situationist critique is typically framed in terms of responsibilist virtues, Alfano (2014) has recently extended the challenge to virtue reliabilism. Cf. Carter \& Pritchard (2016) for a reply to these arguments on behalf of a modified form of virtue epistemology.
} 
defensible, the question remains whether: (1) we can successfully organise educational activities around it (organisation claim), (2) whether we know how to maximise it effectively (value maximisation claim), and (3) whether it outranks all other teaching methods and activities in importance (obligation ranking claim $)^{18}$. Normative theories in virtue epistemology attempt to provide concrete guidance (especially to young people) regarding how to become more intellectually virtuous; as Roberts and Wood (2007) put it, their theory is 'regulative"19. Such a theory must also provide guidance to teachers. If teachers are to organise all their teaching to maximise intellectual virtue to the (sometimes) exclusion of other goals in their classrooms, it behoves them to have available a method to maximise intellectual virtue. In the next three sections, we will discuss this question of whether the intellectual virtue approach has a successful curriculum and pedagogy at its disposal to satisfy all three claims above. As the intellectual virtue approach takes its inspiration from Aristotle's work, this necessitates a detour through Aristotle's thinking about (a) the nature of the intellectual virtues and (b) the acquisition of and teaching for virtue.

\section{Aristotle's distinction between the intellectual virtues and the moral virtues, and his advice for teaching them}

\subsection{The intellectual and the moral virtues in Aristotle}

Aristotle distinguishes between the moral and the intellectual virtues at the beginning of book II of the Nicomachean Ethics. For Aristotle, the two forms of virtue belong to different parts of the soul - the moral virtues belong to the 'desiring' and the intellectual virtues to the 'rational' part of the soul. (NE 1103a15)

Aristotle identified five intellectual virtues: episteme (scientific wisdom), sophia (philosophic wisdom), nous (intellect or intuition), phronesis (practical wisdom) and techne (craft or technical knowledge).

While all five of these are not always discussed in the same depth as Aristotle's moral virtues,

\footnotetext{
18 Note that the three core claims do not entail a further and much stronger claim to the effect that education ought to be wholly virtue-based-viz., that an education should not foster epistemic standings that are non-identical with intellectual virtues, e.g., knowledge and understanding. The idea is that these other educational values (e.g., knowledge, skills, etc) should be promoted as they stand connected in the right way with intellectual virtues, and not the other way around. Thanks to an anonymous referee for requesting clarification on this point.

19 This term was coined initially by Wolterstorff (1996).
} 
it is clear that Aristotle had a very intellectual picture of virtue and the good life. For instance, towards the end of book VI, Aristotle makes it clear that it is the intellectual element provided by phronesis (in contrast to the habituation element) that brings moral virtue to full virtue. One can also see the importance of the intellectual in Aristotle's picture in the fact that he holds sophia to be the highest form of wisdom. This is confirmed by his remarks in Book X (in particular NE Book X, 7 - 8) to the effect that theoretical wisdom is more valuable than practical wisdom.

It is strange if someone thinks that politics or practical wisdom is the most excellent kind of knowledge, unless man is the best thing in the cosmos. (1141a20-22)

In this vein Kraut holds that, for Aristotle, theoretical wisdom is more important than practical wisdom and that practical wisdom stands in service of theoretical wisdom; he also stresses that Aristotle held the life of the philosopher to be the most happy (happier than the life of the politician). (Kraut 1989: 15 - 77)

All of that said, there still exists debate regarding the precise nature of Aristotle's intellectual virtues. In particular, there is disagreement about whether the intellectual virtues are (1) bodies of knowledge, understanding or theory that a person possesses, or (2) the faculties needed to gain such knowledge. ${ }^{20}$ Moreover, Aristotle says little about the acquisition of the intellectual virtues besides saying that they are given in primitive form by nature and are perfected through teaching. Compared to the limited discussion of the acquisition of the three theoretical intellectual virtues, Aristotle does provide a fuller discussion of techne; most of all, however, NE Book VI deals with phronesis. One may say that NE Book VI is really about how phronesis is different from the other four intellectual virtues, and that, in the context of that book, the other four intellectual virtues serve mainly as a contrast to phronesis. So much for Aristotle's own picture of the intellectual virtues.

Contemporary accounts of the intellectual virtues diverge from Aristotle's own account in that most contemporary authors conceive the intellectual virtues not as wisdom in different domains of thought, but as one of two further things, either: (1) well-functioning cognitive faculties (such as sight, hearing or, even, memory) (these are the 'reliabilist intellectual virtues' given importance by, for instance, Sosa, 2009) or (2) the responsible habits one employs in one's thinking (such as being curious, creative, honest, open-minded, etc.) (these are the 'responsibilist intellectual virtues' stressed by, for

\footnotetext{
${ }^{20}$ For an overview, see Baehr (2014). For discussion see Conway (2000), Kenny (1992) and Kraut (1989).
} 
instance, Montmarquet, 1993, Zagzebski, 1996, and Baehr 2011).

Contemporary virtue epistemology does not draw on Aristotle's own division of the intellectual virtues into the theoretical and the practical intellectual virtues as much as one would expect; in fact, one may say contemporary authors on the intellectual virtues draw more inspiration from Aristotle's writing about the moral virtues than his intellectual virtues, strictly speaking. This is evident in the work of Zagzebski when she analyses the intellectual virtues in terms of the moral virtues (1996: Part I, section 1 and Part II, section 3); in the work of Baehr when he discusses how intellectual virtue is a matter of 'personal worth' (2011: chapter 6); and in the work of Roberts and Wood who focus, in their account of individual intellectual virtues, on those virtues that can be both moral and intellectual (2007: chapters 6 - 12). Quite simply put, when they discuss intellectual virtue, contemporary virtue epistemologists have in mind characterological traits like firmness, courage, caution, humility, autonomy and generosity (high on Roberts and Woods's list) as well as openmindedness (high on Baehr's list). All of these virtues describe something about how a person is as a thinker or how they conduct their thinking. This is in contrast with Aristotle's own picture according to which the intellectual virtues are not traits that describe how a person thinks, but more like a domain or mode of thinking that is specific to the subject matter of what they think about. In Aristotle's original formulation, after all, phronesis is excellence in thinking about morality and politics, techne is excellence in thinking about craft, episteme is excellence in thinking about the natural world and sophia is excellence in thinking about philosophy. As it turns out, contemporary responsibilist virtue epistemologists, while inspired by Aristotle, are not purely Aristotelian in their approach. This is not only a matter of the correct interpretation of Aristotle. Modelling their conception of the intellectual virtues on Aristotle's moral virtues also has implications for how contemporary virtue epistemologists conceive of the acquisition of the intellectual virtues.

\subsection{The acquisition of the virtues in Aristotle}

It is important to notice that contemporary responsibilist virtue epistemology models its conception of the intellectual virtues on Aristotle's moral virtues for the following reason: Aristotle and his commentators tell a rich story about how the moral virtues are learned or acquired, but - with the exception of phronesis - comparatively little attention is given in the literature to how Aristotle's intellectual virtues of techne, sophia, nous and episteme are acquired. One suspects that it is partly because the tradition gives us little to work with, and partly because virtue epistemology has always modelled 
itself on virtue ethics, that virtue epistemology has imported its picture of how the intellectual virtues are acquired from Aristotelian accounts of how the moral virtues are acquired. ${ }^{21}$

Aristotle sketches his account of the training of the virtues in NE Book II. For Aristotle, the training of the moral virtues happens through repeated practice of the right kind of action. As Aristotle himself puts it:

...habits are born of similar activities. So we have to engage in behaviour of the relevant kinds, since the habits formed will follow upon the various ways we behave. It is no trivial matter, then, that we form habits of one kind or another right from childhood; on the contrary, it is very important, indeed all-important. (NE 1103b21 - 25)

The classic account of learning to be virtuous in Aristotle is found in Burnyeat. On Burnyeat's reading of Aristotle, through the repeated performance of the virtuous act we: (1) learn how to do the act, (2) perceive the goodness of the act (that it is indeed virtuous), (3) experience appropriate pleasure in doing the act, and (4) develop the desire to do the act for the sake of the goodness of it. (Burnyeat 1980; Porter, 2016: 38) In all of this, learning by example through practice is so important, because for Aristotle, one cannot give rule-like descriptions of what the virtuous thing is to do. What is virtuous is relative to the situation that one finds oneself in and is also relative to who is performing the action. A teacher can make clear what the virtuous thing to do is only by holding up an example of a virtuous action and encouraging young people to copy that example in practicing how to be virtuous. This example may be provided either by the teacher herself (as a moral role-model) or can be provided by the teacher holding up the example of moral exemplars to her students (Aristotle himself found many of his most famous exemplars in Greek mythology).

\subsection{Acquiring the intellectual virtues: the contemporary picture}

Contemporary epistemological accounts of how the intellectual virtues are acquired also borrow this picture of virtue acquisition as habituation from Aristotle's account of how the moral virtues are acquired. Annas, for instance, (2011) holds that the acquisition of virtue is like the

\footnotetext{
21 Note that, in what follows, we only focus on the acquisition of the responsibilist intellectual virtues. This is not to take a position in the reliabilism/responsibilism debate, but because this is a paper about how one can learn and teach good thinking. The reliabilist virtues, such as good sight or hearing, are not learned as such and it is not clear that they can be much improved by learning or teaching. We focus, therefore, on the responsibilist virtues.
} 
acquisition of a skill, like playing the piano, playing tennis or building a house. Annas points out that while it is possible to give some instruction in practical tasks, mastery of a practical skills comes through practice, often under the guidance of a master. The master models performance of the practical task for the novice, giving the learner initial guidance how to perform the task. The learner of a skill then needs to practice independently, until they can perform the practical task for themselves. Finally, the truly skilled person aspires to improve and to push their skill beyond even that of their master. (2011, 17 - 18) Annas holds that acquiring moral virtue works in the same way. A moral role model instructs the learner, the learner practices to be virtuous by copying the master and, eventually, comes to possess full virtue themselves, that they then continually strive to improve.

A number of important questions exist about this picture of the acquisition of virtue, for instance: (a) how does the novice recognise the moral virtuousness of the exemplar, (b) how does the novice draw on the examplar's example to become virtuous themselves and (c) how does the novice conduct moral practice?

Zagzebski's exemplarist theory of virtue acquisition answers these questions. For Zagzebski,

We learn through narratives of fictional and non-fictional persons that some individuals are admirable and worth imitating...' $(2017,15)$

These people are moral examplars. For Zagzebski, there is no set of describable moral characteristics that makes a person an exemplar, rather, the exemplar of virtue is analytically prior to characterisation of the examplar. Borrowing Putnam and Kripke's idea that we understand the meaning of kind terms through ostension, Zagzebski proposes

that basic moral terms are anchored in exemplars of moral goodness, direct reference to which are foundational in the theory. Good persons are persons like that, just as gold is stuff like that. Picking out exemplars fixes the reference of the term "good person" without the need for descriptive concepts. $(2017,15)$

That is, we do not understand what it is to possess a particular virtue like 'honesty', first and then understand that a person like Lincoln is honest; rather, we understand what it is to be honest on the basis that all honest people are like honest Abe.

Zabzebski holds that we identify exemplars through the emotion of admiration. This emotion is not innate, but is shaped through the stories that other people tell of real and fictional moral exemplars. $^{22}$ (Zagzebski, 2017,15) The educable emotion of admiration drives the learner to emulate

22 Sherman (1989) also stresses the importance of the education of the emotions. For Sherman, educating the emotions is a rational process and she leaves more room for direct instruction in her account than Zagzebski, who 
exemplars. Emulation is moral practice and, through moral practice, the learner becomes like her exemplars. As Zagzebski puts it:

The model I am proposing starts with admiration of an exemplar, which leads to an imaginative ideal of oneself, which in turn produces emulation of the exemplar's motives and acts. The moral learner does the virtuous act from a virtuous motive because the learner is emulating someone who does that act from that motive. With practice, the agent becomes disposed to doing acts of that kind from motives of that kind. (Zagzebski, 2017, 138)

While Zagzebski casts the basic features of her examplarist theory in terms of moral exemplars and moral development, her picture of intellectual development is the same. She writes:

I think we admire intellectual virtues in the same way we admire the moral virtues. The intellectual honesty and selfless open-mindedness of C. P. Snow's character, Arthur Miles, is admirable in the same way honesty is admirable, and it is admirable in the same way selfsacrificing virtue of any kind is admirable. $(2017,39)$

The intellectual virtues are then also learned through admiration and emulation of the intellectual exemplar, just like the moral virtues are learned from the moral exemplar.

Moving to practical suggestions for how the intellectual virtues can be taught (and showing great affinity with Zagzebski's work), Heather Battaly holds that there are three main methods for inculcating the virtues - formal instruction, the imitation of exemplars and practice. (Battaly, 2016, 171) For Battaly, the role of formal instruction about the virtues is to introduce students to what the virtues are.

Formal instruction - lecturing about intellectual virtues and their value - introduces students to new categories, which they can apply to the world and themselves. (2016:173)

Moreover, Battaly holds that formal instruction can help identify exemplars - that is, others who are virtuous - to provide students with examples of virtue in action that they can try to copy. As she puts it:

stresses the importance of the exemplar. Still, for Sherman, learning to be virtuous essentially happens through imitation (mimesis) and we direct our attack mostly at imitation as a method for learning to be rational. See Sherman $(1989,166-8)$. 
...in describing intellectually virtuous agents and their actions and motivations, we provide students with specific targets at which they aim... (Battaly, 2016, 173)

However, Battaly stresses that formal instruction in the virtues - that is, being taught directly what the different virtues are and what they demand of one - cannot provide one with anything like rules for virtuous action. This is because there can be no rules that specify what it is to be virtuous: virtue is relative to person and to situation. (Battaly, 2016: 172) In the absence of 'rules of virtue' Battaly holds that the only way to give guidance regarding what a person should do is to point towards exemplars of virtue - people who personify virtue in how they act. (Battaly, 2016: 173) In the end, she proposes the following strategies for teaching intellectual virtue:

(1) Use formal instruction to explain the... virtues; (2) use exemplars to further elucidate individual... virtues; (3) provide opportunities to practice identifying virtuous actions, emotions, and motivations; (4) use exemplars to help students experience virtuous emotions; (5) provide opportunities to practice performing virtuous actions and having virtuous emotions and motivations; and (6) provide opportunities to practice virtuous perception.

Other authors broadly agree with Battaly in how they see the teaching of intellectual virtue proceeding in the classroom. Robert Roberts holds that classroom teaching for one intellectual virtue (the virtue of intellectual humility) should proceed by: modelling, practice, critical thinking ${ }^{23}$ and identifying virtues and vices. (2016: 196 - 201) And Steven Porter holds that the 'standard approach' to teaching virtue includes:

'(1) Direct instruction on the nature and importance of virtues; (2) exposure to exemplars of the virtues; (3) practice of virtuous behaviours and the resultant habituation of virtuous dispositions; and (4) crafting environments that inculcate virtue.' (Porter, 2016: 222)

All three of these authors lean heavily on exemplars and practice in their approaches to teaching intellectual virtue, illustrating that exemplarist thinking (a la Zagzebski) underpins thinking about the teaching of intellectual virtue.

\footnotetext{
${ }^{23}$ It is notable that Roberts recognises the importance of critical thinking. He does not, however, fit critical thinking into his account of what intellectual virtue is systematically.
} 


\section{Inculcating intellectual virtue: the problem of providing direction through teaching}

Above, we saw how virtue epistemologists lean on exemplarist thinking in their recommendations for how to teach intellectual virtue. According to this picture of the acquisition of the intellectual virtues, the intellectual virtues cannot be described exactly; they can only be modelled. Moreover, while one can teach about the intellectual virtues, one cannot directly teach for the intellectual virtues. The best we can do is to hold up the right example and get students to practice to become like that example through imitation. In this regard, a natural question arises: what if, despite the fact that one holds up the best examples of intellectual conduct and encourages students to practice good intellectual conduct, they simply do not 'get it'? For instance, suppose a teacher holds up example after example of people who were intellectually courageous - for instance Copernicus, Jenner and Curie - and also conducts herself in a way that is intellectually courageous. Suppose that, moreover, the teacher gives the students ample opportunity to practice being intellectually courageous in an atmosphere in which intellectual courage is supported and rewarded. Say, though, that the teacher's students do not come up with a single intellectually courageous thought between them. What direct advice, guidance or instruction can the teacher give to the students about what they should do to be more intellectually courageous?

In this vein, virtue ethics has long been criticised for not being directive or action guiding enough. An excellent account of this objection is found in Louden. Louden observes that what people expect of any ethical theory is:

to tell them something about what they ought to do and it seems to me that virtue ethics is structurally unable to say much of anything about this issue... (Louden, 1984: 229)

Louden holds that we can expect three things from a practical ethical theory: Firstly, we expect practical ethical theories to provide us with justification for acting one way rather than another. Secondly, we expect a practical ethical theory to give us guidance or direction that will help us work out what to do in ethically difficult situations. Thirdly (and most importantly in this context), Louden thinks we can expect of an ethical theory to provide guidance to novices regarding what to do (or, perhaps, guidance to more mature people who find themselves faced with a new ethical problem). As to the third matter, Louden holds that virtue ethics is often 'too vague and unhelpful for persons who have not yet acquired the requisite moral insight and sensitivity'. (Louden, 1984: 230) The problem is that saying 'be honest' does not provide a route-map to right action if one does not know what honesty 
in a situation like this amounts to. Just so, enjoining someone to copy the example of another person - for instance, directing them to 'be like honest Abe' - does not provide someone with instruction on what to say or not to say in a particular situation if they do not already know what honest Abe would have done in that situation. ${ }^{24}$

In the wake of Louden's work, a number of other authors have taken up the theme of whether virtue ethics is or is not sufficiently action-guiding. Solomon (1988) agrees with Louden that virtue ethics is not action guiding. Moreover, he adds that character is not under one's control in the same sense as one's actions are. At the time that one must act, one cannot immediately change one's character, however, one can choose to act one way rather than another. (1988: 431-3) Like Solomon, Sher (1998) also focuses on the ability or inability of virtue ethics to provide action guidance. Sher links the two separate points that Solomon makes regarding action guidance and control. Sher holds that any real guidance for action must, in providing that guidance, focus on what is under one's control. Guidance that cannot be implemented is ineffectual guidance, and accordingly, useful guidance must be guidance that can be implemented. Solomon and Sher see the problem with virtue ethics's actionguidingness in a particular way. The reason that virtue ethics fails to provide good guidance for action is that all the advice it gives is at the wrong level of decision making.

Both Solomon and Sher acknowledge that virtue ethics may provide guidance about how to live a life overall or over the long term. They hold that virtue ethics can provide guidance about how to improve one's general conduct; for instance, virtue ethics offers the sound guidance that, over the course of one's whole life, one should try to be kind, forgiving, generous, appreciative and so-on. However, in addition to advice for how to live one's life overall, one expects from ethical insight something else: implementable guidance about what to do about a specific dilemma or quandary we are faced with at a particular time. As Sher writes: 'although our lives are spread over many years, we live them one moment - and (roughly) one action - at a time'. (1998: 16) While injunctions like 'be honest', 'be brave' or 'be kind' no doubt contain good long-term advice about how to live a life, 'be honest', 'be brave' or 'be kind' is not specific advice about how to deal with a specific moral problem.

\footnotetext{
${ }^{24}$ Note that this problem may be compounded in cases where those receiving the instruction manifest intellectual vices. As Alessandra Tanesini (2016) puts it, those 'who are the furthest away from intellectual virtue are precisely those who are less likely to pay attention. Exposure to exemplars might work only if it stimulates emulation. It is counterproductive if it leads to demoralisation or if it fans an already inflated conception of the self. Sadly, those [...] who have developed non virtuous habits are most likely to react to models in precisely these ways $(2016,524)$.
} 
In the virtue ethics literature, a number of figures hold that virtue ethics does provide timely and implementable action guidance, among them Slote (2001), Swanton (2003) and, most notably Hursthouse (1999). According to Hursthouse's 'qualified agent account':

Qualified Agent Account ( $Q A A)$ : an action $\varphi$, performed by Agent A is right in circumstances c iff a fully virtuous person $\mathrm{E}$ would perform $\varphi$ in c.

Two particular objections have been offered to this and similar attempts to derive implementable action rules from a hypothetical description of what the virtuous agent would do. ${ }^{25}$

The Error Problem: While it is good general advice to be like the virtuous person, on occasion the non-virtuous agent should do what a virtuous person would not do. For instance, part of what it is to be virtuous is to love doing the virtuous thing. Because they love virtue, the fully virtuous person does not struggle to do the virtuous thing. However, the not-quite-virtuous person often struggles to do the virtuous thing and might need to perform decidedly nonvirtuous things in order to act in a way that is more or less right or that is not outright vicious. (Johnson, 2003)

The Failure Problem: Sometimes the non-virtuous agent finds herself in a situation that a virtuous person would not be in and, in such a situation, the advice 'do what the virtuous person would do' provides no concrete action guidance. For instance, it is a sad fact that one's misdeeds mount up: taking one misstep sometimes leads one deeper and deeper into wrongdoing and then it is difficult to know how to extricate oneself. The truly virtuous person would never get themselves into a situation where their previous misdeeds have left them compromised; so there is no answer to the question 'what would a truly virtuous person do in this morally compromised situation'. (Harman, 1983)

\footnotetext{
25 We are indebted in what follows to Van Zyl (2011a; 2011b) who discusses the problems with the qualified agent account.
} 
In situations like these, saying 'be virtuous' or 'be like this moral examplar' does not help the ethical novice to know what actually to do or how to bring themselves to do it. ${ }^{26}$

So far we have focused on the failure of moral virtue and moral examplars to provide action guidance. What about intellectual virtue and intellectual examplars? Do they provide guidance concerning how to think well? Here things are not especially promising. Just like moral virtue struggles to provide concrete action guidance, the injunction 'act like an intellectually virtuous person would' does not provide concrete guidance regarding how to think in an intellectual dilemma situation either. Take two cases analogous to Van Zyl's error and failure problems.

The Intellectual Error Problem: A dishonest and vain politician knows that one of his major intellectual faults is exaggeration and he has been trying for some time to rein in this bad habit. At a press conference, a journalist asks a probing question about one of his party's policies that the politician does not know how to answer. The politician knows that he could improvise an answer on the spot, but knows that this is likely to involve exaggeration and dishonesty. Trying hard not to get drawn into extemporising an answer, the politician instead gives a pat and condescending answer to the thoughtful question, shutting the journalist down and moving on to take the next question. The politician's behaviour is not intellectually virtuous. The intellectually virtuous person would admit their ignorance, but share with the audience whatever it is that they know about their party's policy in an open way, engaging in honest, exploratory dialogue about what the party's policy should be on the particular issue. Trying to do this, however, would draw the politician into the kind of extemporising that he knows he had better avoid, so, while we do not admire the politician in wriggling out of the question, that may still have been the best thing for him to do in this situation.

The example shows that, in our intellectual conduct, non-virtuous people sometimes should perform actions that virtuous people would not perform, exactly because they are not (yet) virtuous.

\footnotetext{
26 Van Zyl (2011a: 87 - 91) does suggest her own account of how to derive action guidance from hypothetical action by the virtuous: one should note not just what a virtuous person would do, but also what a vicious person would do in a particular situation and the conjunction of these two make available a zone between the virtuous and the vicious in which the novice can choose how to act. Van Zyl's solution only narrows down the region in which the ethical novice must choose, however, it does not tell her exactly what to do.
} 
The Intellectual Failure Problem: A student did not study for a logic test that she knows will involve evaluating propositional arguments using the 'truth trees' method. The student skipped the class on truth trees, but she remembers how to evaluate arguments using the 'truth table' method, so, on the day, she evaluates the first few arguments on the test using the truth table method. Then, running out of time, she gamely writes at the bottom of the test: 'The truth trees method works a little like this, but it is quicker because you don't have to write everything out!'

It is clear that a virtuous student would not land in a situation like this; a virtuous student would have attended the class on truth trees and would have practiced evaluating arguments using the truth trees method before the test. Because an intellectually virtuous student would not be in a situation like this, saying 'act like an intellectually virtuous student would' provides no guidance to our student what to do. Even so, there is something to be said for how our student conducted herself during the test: she demonstrated a willingness to try, a degree of insight into how the truth trees method works, and even a sense of humour. Her logic teacher may even give her a few marks on the test for effort, showing that what one should do is not always well predicted by what the intellectually virtuous person would or would not do.

The examples above generalise from students and politicians to anyone engaged in day to day intellectual problem-solving: For instance, it is not particularly helpful to tell a ship's captain to be 'intellectually careful' in planning a hazardous sea journey; instead of being general advice regarding how to conduct himself, the captain needs concrete passage planning advice to ensure that the ship arrives at her destination safely and on time. Just so, the advice that is really useful to the novice thinker is not general advice about epistemic responsibility, but concrete advice about what moves to make and what moves to avoid in their thinking. As Coady (2012) puts it in a different context, our main epistemic challenge is to know 'what to believe now' and intellectual virtue provides the wrong level of advice in this regard. ${ }^{27}$

27 Granted, some Aristotle scholars (like Sherman 1989) hold that Aristotle's picture of emotion actually includes a rational element and that the emotions can be educated. Sherman makes the case that learning through imitation is a rational process and that, by directing the learner's attention to the morally relevant features of the exemplar's conduct, the teacher does help to guide the learner through their moral practice. (1989, 180 - 1) Important to note, however, is that Sherman gives most attention to how the emotions are educated: that is, to how the teacher can draw attention to the admirable features of exemplars' conduct and, thereby, make it clear what the student should emulate about the exemplars and why. The point is well made. However, Sherman still insists that teaching the learner bow to emulate the teacher will not be 'procedural'. $(1989,181)$ This creates a curious disjunction in Sherman's thought: on the one hand, she holds that an emotion like admiration can be directly taught; on the 
In sum, our worry about teaching of the intellectual virtues is this. Advising children to be intellectually honest, brave or rigorous if they want to become intellectually virtuous thinkers and enjoining them to imitate intellectual exemplars does not amount to specific advice regarding how they can improve their thinking. This is especially so if the student is, for the moment, quite far from being intellectually virtuous. Above, we asked: (1) Does a focus on teaching the intellectual virtues provide us with a way to organise a curriculum for teaching thinking (organisation claim)?, (2) does it provide us with a pedagogy for teaching thinking skills in a step-by-step way (value maximisation claim)?, and (3) does it outrank all possible other teaching methods and activities in importance (obligation ranking claim)? This section presented our answer regarding point (2). Intellectual virtue does not provide a pedagogy that helps children with the nuts and bolts of the intellectual problems they face, like: how to evaluate this argument or how to solve this mathematical problem or how to interpret this poem. For these specific intellectual problems we can provide more concrete guidance via another route. In section 5 , we go on to say what that route is.

\section{The Critical Thinking Approach}

By contrast with teaching the intellectual virtues, another very well-established tradition can lay claim to accomplishing (1), (2) and (3): the tradition of teaching Critical Thinking - understood broadly as the theory and principles of good reasons and reasoning - in order to improve thinking. The Critical Thinking (CT) approach does what we've claimed the IV approach does not: it teaches students what critical thinking is, why it is good (and why uncritical thinking is bad), and how to think critically. By 'good' here we mean good from the epistemic point of view - that is, thinking that passes epistemic muster in that it offers truth-directed reasons and evidence that are probatively forceful, that avoids fallacies and other mistakes in reasoning, and that is informed by a broad understanding of epistemic quality and an appreciation of the criteria in terms of which that quality is determined, both

other, she holds that there is no teachable standard for virtuous conduct: what is virtuous will always depend on judgement, emotion and context all together and one cannot specify in a rule what virtuous conduct is. $(1989,179)$ The problem is that merely educating the intellectual emotions will only get our students so far. Even if students know who are good intellectual role-models and know what is good about their intellectual role-models' conduct, students still need more information to enable them to reason as well as their intellectual role-models do. In order to reason well, the learner needs to ensure that the substance of their thinking is like their intellectual role-model's thinking; that is, students need to learn how to make their thinking measure up to the standards of rationality attained by their role-models' thinking. To enable them to do this, they need more than imitation. They need to learn what those standards of rationality are and need to learn easily understandable procedures to help them attain those standards of rationality in their own thinking. 
in terms of general criteria sanctioned by logic (both formal and informal), probability theory, and epistemology, and of subject-specific criteria sanctioned by particular subject areas. In addition to the items just mentioned, the CT approach includes instruction in argument analysis, argument structures, argument schemes, arguments couched in both print and ordinary speech, rhetorical moves and their epistemic and other features, etc. The CT approach also emphasizes the epistemology underlying CT: what a reason is, what evidence is, how these provide probative support, how the character of such support is best understood, how it relates to justification and truth, etc. 28

Compared to the intellectual virtues approach, the CT approach has a number of distinct advantages.

\subsection{The benefits of systematisation}

Many of the advantages of teaching thinking through logic have to do with the benefits of systematising the evaluation and solution of problems in thinking. It is beyond the scope of this article to provide a history of logic. ${ }^{29}$ However, it is as well to bear in mind that many of the great advances in logic were all formalisations of areas of thinking. Syllogistic logic formalises thinking about class or category membership, propositional logic formalises the meaning of logical connectives (and the propositional arguments that we can create, using these connectives), and predicate logic combines both, enabling logicians to formalise any deductive argument in natural language and evaluate its validity. The advantages of these innovations in formal logic lie in how it enables one to see right into the logical form of deductive arguments and to evaluate whether an argument is valid or not. Thinking about 'the nature of good thinking' in logical terms has the advantage over thinking about it in virtue terms that it is completely precise and un-ambiguous. If one were to characterise what good thinking is in virtue terms, one would have to point to paradigm thinkers and say 'good thinking is like that'. However, appealing to logic, we need not be so vague - we can capture what good thinking is in a set of principles.

Admittedly, that it is a formal pursuit is most clear in the case of formal logic, and 'informal logic' purposely avoids too much formalism in teaching logic, choosing instead to use natural language as far as possible. This is not too say, however, that informal logic does not draw on the insights of

\footnotetext{
28 While this epistemological dimension is fundamental to the CT approach, we do not emphasize it here.

${ }^{29}$ For the most complete history of logic, see Gabbay and Woods (eds) Handbook of the History of Logic (several volumes).
} 
formal logic or avoids all formalisation. Informal logic uses some formalisation too, for instance in diagramming arguments (rather than translating them into propositional or predicate calculi). Moreover, informal logic uses many of the same logical concepts that formal logic uses and evaluates the validity of arguments according to the same criteria. While informal logic avoids using the language of formal logic, it still evaluates natural language arguments by fitting them into forms that mirror, or approximate, what we would achieve using the language of formal logic. While informal logic is not formal, it is, at least, systematic.

Next to being precise, formal and informal logic has achieved enormous coverage in explaining good thinking in one coherent system. If we conceive logic broadly enough and include, next to deductive logic, also inductive logic (and its applications in statistics and probability) and modal logic, we can formalise very large swathes of all thinking and evaluate its rationality. Put quite simply, the study of logic, broadly construed as we have done so here, provides the clearest, most precise and most comprehensive account of good thinking that we have by far. More importantly, over and above the teaching of logic (both formal and informal), the CT approach emphasizes the study of the epistemic criteria by which arguments specifically, and reasons more generally, are evaluated. It is hard to see anything more fundamental to the determination of good thinking. Instances of intellectually virtuous thinking, if they are indeed good, will be so only because their quality satisfies such criteria.

Conceiving what good thinking is in logical/epistemological terms (rather than in characterological terms) has the following concrete advantages for the teacher. Drawing on logical systematization and criteria of epistemic quality helps the teacher to strip away unnecessary detail and to focus on the form, content, and epistemic support relationships of arguments in discussing them with her class. It helps the teacher easily to generate arguments to evaluate. And it provides a step-bystep and cumulative way to evaluate arguments that she can teach to her students. Rather than having to rely on role-modelling or exemplars to exemplify good thinking, the teacher who appeals to logic again, understood broadly, as we have done here - can explain with precision to her students what good thinking (and bad thinking) is. Moreover, she can offer clear reasons (that are not context or person-relative) as to why that form of thinking is good or bad.

\subsection{Dealing with cognitive biases and fallacies}

A second advantage of the CT approach lies in how it makes use of psychological research in understanding and promoting good thinking. According to psychological research, we are prone to 
many mistakes that seem deeply ingrained and difficult to overcome - we neglect base rates in estimating probabilities, we give too much weight to evidence that confirms our existing beliefs and too little weight to evidence that challenges them, we take our idiosyncratic experiences to be indicative or representative of people's experiences generally, etc. ${ }^{30}$

There is a large, ongoing debate concerning the proper lessons to draw from the psychological research. Does it show that humans are irredeemably irrational? Are the alleged flaws not really flaws at all, but rather reasoning shortcuts (rules of thumb) that sometimes lead us astray but are mainly good? We will not wade into these debates here. Instead, we will briefly argue that the CT approach is well-positioned to take this evidence into account and use it to further enhance students' critical thinking abilities, but that the IV approach is not.

Our claim here is straightforward: the CT approach is fully engaged in studying the quality of reasoning and arguments, both good and bad, and the problematic tendencies can be readily illustrated and analysed so that students can be on alert for them, both in their own thinking and in the thinking and arguments of others. For example, students can be given the 'Linda' case (Tversky and Kahneman 1983) in which subjects routinely violate the conjunction rule of probability theory by judging it more likely that Linda is both a bank teller and active in the feminist movement than that she is one or the other (but not both). By first thinking it through for themselves, then studying the reasoning involved - and in particular, the reasons for thinking that two independent facts or events cannot be more likely than either one of them by itself (it can't be more likely that the apple is both green and rotten than that it is one or the other) - they can, with proper instruction, both appreciate why the violation is a mistake and learn to recognize and so avoid it.

On the other hand, the IV approach seems unable to incorporate psychological research on human reasoning into their pedagogical toolkit. Recall its two techniques: role-modelling and exemplarism. Teachers can role-model good thinking by engaging in it. So consider the IV teacher role-modelling the avoidance of the conjunction rule mistake. They can of course reason in accordance with the rule, thereby avoiding the mistake. ('So you see, it cannot be more probable that Linda is both a bank teller and active in the feminist movement than that she's one or the other.') But modelling the reasoning will involve articulating it, explaining why probability theory dictates that violations of the conjunction rule are mistakes, etc., which goes beyond modelling and involves instructing: teaching,

\footnotetext{
30 A brief but telling review of the psychological literature on reasoning foibles and its implications for the CT approach is offered in Battersby 2016.
} 
explaining, justifying, answering questions and objections, etc. The same is true of exemplarism: the teacher can hold up examples of right-thinking probability theorists ('Look how Pascal, Fermat, Kolmogorov, and de Finetti addressed this topic'), but in order for students to appreciate the wisdom of the exemplars, the same instruction is required. In short, it will not be enough to model or exemplarise reasoning that avoids the foibles that psychology of reasoning research has brought to our attention. Rather, explicit instruction will be necessary to help students spot and avoid them.

What is the case for cognitive biases is also the case when it comes to studying and combating fallacious reasoning more broadly. While they are not all yet studied in psychology and while they may not all have an explanation in terms of some cognitive bias that all humans share, philosophy has long studied forms of arguments that are invalid, but commonly persuasive. These are the fallacies and, since classical times, philosophers have identified many fallacies, classified them and explained why they are fallacious. For most fallacies, explanations regarding why they are fallacious are possible to give in both natural and formal language. We have already explained (in this section) the advantages of instructing about cognitive biases, what they are and how to avoid them. The same goes for fallacies more broadly. Instructing students in the avoidance of the fallacies is a much more direct and precise teaching strategy compared to modelling their avoidance ${ }^{31}$.

\subsection{The CT curriculum}

A further advantage of conceiving good thinking in terms of logic, broadly understood to include epistemology and criteria of epistemic quality, rather than in terms of intellectual character, is the availability of a large and established curriculum for teaching logic and critical thinking. As we saw in section 5.1, the logical/epistemological study of good reasons and reasoning has managed to map out what good thinking amounts to in one broad, interlocking system. That same system has been turned into a curriculum for teaching reasoning that has been followed for decades in schools and universities. This curriculum is taught across a number of different subjects in schools and universities - sometimes called 'Critical Thinking', sometimes 'Informal Logic', sometimes 'Logic', sometimes even 'Applied Epistemology'. But the outline of this curriculum is well-known and scholars agree in both theory and practice what should be taught as part of introductions to the subject. This curriculum is widely taught in philosophy departments across the world and there is solid evidence that it is

\footnotetext{
31 See, for example, Hamblin (1972) and Hansen and Pinto (1995).
} 
successful when taught well. ${ }^{32}$ By contrast what curriculum one should use to teach children to be intellectually virtuous is much less clear. As we saw above, advocates of the IV approach propose teaching the meaning of intellectual virtue words directly and use role-models and exemplars to ensure that children understand what the intellectual virtues are and use practice to ensure that intellectual virtue takes root. However, advocates of the IV approach deny that there can be a set of rules or procedures for teaching intellectual virtue. In so doing, they all but deny that there can really be a stepby-step guide for teaching good thinking - all that there can be are numerous good examples. The approach derived from logic shows the advantage of systematizing the content of what children should be taught about thinking for the teacher. It provides a road-map for teachers to teach good thinking rather than merely an approach or an orientation. ${ }^{33}$

\subsection{Assessing good thinking}

As we saw in section 5.1, the study of logic again, broadly conceived, has furnished philosophers with a good understanding of what good thinking amounts to in the round. In 5.3 we saw that philosophers have turned this into a curriculum for teaching thinking. One particularly important adjunct to being able to teach any subject with precision is to be able to assess the effectiveness of one's teaching with precision. A teacher who is teaching systematically must be able to make sense of what their students know or can do. The knowledge that a teacher has of her students' knowledge is called 'assessment'. Assessment helps teachers to know what knowledge students bring to some course of study independently of what she tries to teach - knowledge of students' pre-existing knowledge helps the teacher to know where to start in her teaching. If the teacher knows what her students know after the completion of some course of study, she can see what and how much her students have come to know. She can also keep track of whether her students have come to know all that she intended to teach.

The fourth advantage of the CT approach to teaching good thinking that we would like to outline is that it has available a good set of tests that accomplishes this. As one of us (Kotzee 2016) has outlined, the assessment of critical thinking is much more advanced than the assessment of

\footnotetext{
${ }^{32}$ For a review of this research, see Ennis 2016.

${ }^{33}$ In this respect, on the CT view, logic/epistemology are placed 'pedagogically first'. Thanks to a referee at Episteme for suggesting this terminology.
} 
intellectual virtue and empirical assessment of virtue development in students is decades behind the methods we already possess for assessing critical thinking ability.

In the end, the pedagogical challenge for the intellectual virtues approach to education is the following. As philosophers, advocates of the intellectual virtues approach well know how crucial the teaching of logic, broadly conceived, is in promoting good thinking. When forced to decide what to prioritise in a classroom - teaching good reasoning a la the CT approach, that is relatively clear, implementable advice that can definitely improve thinking, or (trying to) teach intellectual virtue that is context and person-dependent, is at a very general level of advice, and that is not always measurably effective - are they really willing to risk giving up the former for the latter?

\section{A unified approach?}

In section 5, we outlined a number of advantages of the CT approach to the teaching of thinking over the IV approach. In this section, we would like to rebut a likely objection to our approach. In an unpublished exchange, Baehr has suggested that one should not see the intellectual virtues approach and the critical thinking approach as pure rivals. Rather, he holds that one can conceive the critical thinking approach as part of a broader intellectual virtues approach. Specifically, Baehr holds that being intellectually virtuous comprises both being able to reason well and being motivated to reason well into one characterological state that encompasses an ability to reason well and a love of truth to such an extent that the agent is virtuously inclined to reason well. Is it not possible, as Baehr suggests, that all of what we have outlined as the 'logical' approach to thinking forms the first (reasoning) part of intellectual virtue? Can scholars in the IV tradition not cheerfully accept all the advantages of understanding good thinking in terms of logic and critical thinking, and teaching and assessing it as the CT approach suggests, but insist that the teaching of good thinking requires still more than teaching logic - i.e. good intellectual motivation - and that only the IV approach is capable of making sense of this larger matter? Outlining the likely counter-argument positively: the IV approach could accept the logical account of what good thinking is, but insist that that account only makes sense of good reasoning and not of good reasoning and good intellectual motivation fused together in that important characterological state we call 'intellectual virtue'.

Advocates of the IV approach should not be too quick to opt for this approach. While superficially attractive, it would come with a challenge that goes to the heart of the IV conception of good thinking and approaches regarding how to teach it. Recall that on the Aristotelian picture advocated by, for instance, Baehr, Battaly, Roberts and Wood, and Porter there can be no precise rules 
for teaching good thinking. On the Aristotelian picture, virtue is relative both to the person and to the situation that they find themselves in. For this reason, grasp of what virtue is must come not from being told or instructed, but from familiarity with a large number of examples of virtue and personal practice in being virtuous. Accepting that the principles of logic do unambiguously settle what good thinking is and settles this universally (not relatively) clashes with that first very important neoAristotelian assumption about the relativity of the intellectual virtues. ${ }^{34}$ Moreover, accepting that one can teach someone how to think well by direct instruction in the principles of logic and epistemology also clashes with the Aristotelian assumption about becoming virtuous that it requires practice. To be fair, we know that learning logic does take practice, but it is completely possible to teach a student a new principle of logic that, once mastered, they can be said to have grasped; they do not need to see many examples of the same logical principle in action to make it part of their person in some deeper way to understand the principle.

The point is that incorporating the critical thinking picture into the intellectual virtues picture will change the IV picture of what good thinking is and how we become capable of it. This is not a move that advocates of the IV approach can make without opting for a picture of the IVs that make the 'reasoning skill' part of intellectual virtue objective and perspicuous. If they choose this tack, intellectual virtue theorists will have to admit that, after all, virtue is not relative to a person or to a situation. Moreover, they will have to admit that it can be acquired through direct instruction, implying that the function of intellectual exemplars, imitation and intellectual practice would only be to bring children to conform to logical principles (broadly conceived) in their thinking. In short, bringing the CT approach into the IV approach will establish once again that teaching the principles of logic and critical thinking 'outrank' any other educational aim (obligation ranking claim). Incorporating the CT approach into the IV approach would, again, establish that critical thinking is the central thing that teachers can teach for and so make it their primary obligation to teach this. ${ }^{35}$

\section{Conclusion}

\footnotetext{
34 As we have pointed out above, this approach is most likely borrowed from Aristotle's thinking about the person and context relativity of the moral virtues. That Aristotle thought the intellectual virtues were relative in the same way is improbable.

35 We should also point out that Baehr's critique of the CT approach treats that approach as involving only reasoning skills/abilities, while advocates of that approach more or less uniformly regard it as involving both skills/abilities and a complex of dispositions, habits of mind and character traits sometimes referred to as the 'critical spirit.' See Siegel (1988) for a statement of this conception of CT, and Siegel (2016) for a discussion of the extent to which the critical spirit should be understood in virtue terms.
} 
Like most enlightened philosophers and educators, we applaud efforts to help students and others be more virtuous, and to the extent that the IV approach can facilitate that, we support it. Nevertheless, we think that, at present, the approach has insufficient pedagogical tools to do the job. This is especially so in light of the fact that according to proponents of the approach, possession of the virtues requires exactly the abilities valorised by the CT approach. Practically speaking, it is the grasp of reasons and the abilities involved in reasoning well that must be taught - not just modelled or exemplarised - if students are to become intellectually virtuous, critical thinkers, or intellectually virtuous critical thinkers. Realising this is important not only to the pedagogy of good thinking, but to epistemology generally. If we conclude that good thinking can only be taught (or is best taught) in a principles-based way, this provides further good reason to think that objective principles that can be clearly formulated must play a central role in any normative epistemological theory.

\section{References}

Adler, J.E. (2003). 'Knowledge, Truth, and Learning'. In R. Curren, ed., A Companion to the Philosophy of Education, pp. 285-304.

Alfano, M. (2013). Character as Moral Fiction. Cambridge University Press.

Alfano, M. (2014). 'Expanding the Situationist Challenge to Reliabilism About Inference'. In Virtue Epistemology Naturalized, edited by Abrol Fairweather, pp. 103-122. Springer.

Alfano, M. (2012).. 'Expanding the Situationist Challenge to Responsibilist Virtue Epistemology'. The Philosophical Quarterly 62 (247), 223-249.

Aristotle. (1999). Nicomachean Ethics. Trans T. Irwin. Indianapolis: Hacket.

Baehr, J. (2013). 'Educating for Intellectual Virtues: From Theory to Practice'. Journal of Philosophy of Education 47(2), 248-262.

Baehr, J. (Forthcoming). 'Intellectual Virtues, Critical Thinking, and the Aims of Education,' forthcoming in the Routledge Handbook of Social Epistemology, eds. Peter Graham, Miranda Fricker, David Henderson, Nikolaj Pedersen, and Jeremy Wyatt.

Baehr, J. (ed). (2016). Intellectual Virtues and Education: Essays in Applied Virtue Epistemology. London: Routledge.

Baehr, J. (2011). The Inquiring Mind. Oxford: Oxford University Press.

Baehr, J. (2013a). 'The Cognitive Demands of Intellectual Virtue'. In T. Henning and D. P. Schweikard, eds., Knowledge, Virtue, and Action: Putting Epistemic Virtues to Work. London: Routledge, pp. 99-117.

Baehr, J. (2014). "SOPHIA: Theoretical Wisdom and Contemporary Epistemology." In: Virtues and their Vices. Eds. Kevin Timpe and Craig Boyd. Oxford: Oxford University Press, pp. 303323.

Bailin, S., \& Siegel, H. (2003). 'Critical Thinking', The Blackwell Guide to the Philosophy of Education, 181193.

Battaly, H. (2008). 'Virtue Epistemology'. Philosophy Compass 3(4), 639-663.

Battaly, H. (2015). Virtue. John Wiley \& Sons.

Battaly, H. (2016). 'Responsibilist Virtues in Reliabilist Classrooms' In: J. Baehr, ed., Intellectual Virtues and Education: Essays in Applied Virtue Epistemology. London: Routledge. 
Battaly, H. (2006). 'Teaching Intellectual Virtues'. Teaching Philosophy 29(3), 191-222.

Battersby, M. 'Enhancing Rationality: Heuristics, Biases, and the Critical Thinking Project'. Informal Logic 36(2), 99-120.

Bevan, R. (2009). 'Expanding Rationality: The Relation between Epistemic Virtue and Critical Thinking'. Educational Theory 59(2), 167-179.

Broadie, S. (2006). 'Aristotle and Contemporary Ethics' In: Kraut, R. (ed) The Blackwell Guide to Aristotle's Nichomachean Ethics, Oxford: Blackwell, pp. $342-61$

Burnyeat, M. (1980). 'Aristotle on Learning to Be Good' In: Rorty, A.O. (ed) Essays on Aristotle's Ethics. University of California Press, pp. 69 - 92.

Carter, J.A. and Kotzee, B. (2015). 'Epistemology of Education' in Oxford Bibliographies Online: Philosophy.

Carter, J.A. and Pritchard, D. (2016). 'Epistemic Situationism, Epistemic Dependence, and the Epistemology of Education' Epistemic Situationism, (eds.) M. Alfano \& A. Fairweather, (Oxford: OUP), 168-191.

Coady, D. 2012. What to Believe Now: Applying Epistemology to Contemporary Issues. John Wiley $\&$ Sons.

Code, L. (1987). Epistemic Responsibility. Brown University Press.

Conway, D. (2000). The Rediscovery of Wisdom London: Palgrave Macmillan.

Elgin, C. Z. (1999). 'Education and the Advancement of Understanding'. In D. M. Steiner, ed., Proceedings of the 20th World Congress of Philosophy, Vol. 3, Philosophy Documentation Center, pp. 131-140.

Ennis, R.H. (2016). 'Critical Thinking Across the Curriculum: A Vision'. Topoi, published online 10 June 2016, DOI 1007/s11245-016-9401-4.

Gabay, D. and Woods, J. (2004 - 2012). Handbook of the History of Logic Volumes I - II. Elsevier.

Goldman, A.I. (1999). Knowledge in a Social World. Clarendon Press Oxford.

Greco, J. and Turri, J. (2015). 'Virtue Epistemology'. In The Stanford Encyclopedia of Philosophy, edited by Edward N. Zalta, Fall 2015.

http://plato.stanford.edu/archives/fall2015/entries/epistemology-virtue/.

Greco, J. (2010). Achieving Knowledge. Cambridge: Cambridge University Press.

Greco, J. (2003). 'Knowledge as Credit for True Belief. In Intellectual Virtue: Perspectives from Ethics and Epistemology, edited by Michael DePaul and Linda Zagzebski. Oxford: Oxford University Press pp. 111-134.

Greco, J. (2012). 'A (Different) Virtue Epistemology'. Philosophy and Phenomenological Research 85: 1-26. Hamblin, C.L. (1972). Fallacies. Methuen.

Hansen, H.V. and Pinto, R. (1995). Fallacies: Classical and Contemporary Readings. Penn State U Press. Harman, G. (1983). 'Human Flourishing, Ethics, and Liberty', Philosophy \& Public Affairs, 307-322.

Hursthouse, R. 1996. 'Normative Virtue Ethics' In: Crisp, R. (ed) How Should One Live. Oxford: OUP, pp. 19 - 33.

Hursthouse, R. (1999). On Virtue Ethics. Oxford: OUP.

Johnson, R. N. (2003). 'Virtue and Right'. Ethics, 113(4), 810-834.

Kenny, A. (1996). Aristotle on the Perfect Life. Oxford: Clarendon Press.

Kidd, I. J. (2016). 'Educating for Intellectual Humility'. In Educating for Intellectual Virtues: Applying Virtue Epistemology to Educational Theory and Practice, edited by Jason Baehr, 54-70. Routledge.

Kidd, I. J. (2018). 'Epistemic Corruption and Education', Episteme (Online First: doi: https://doi.org/10.1017/epi.2018.3).

Kilby, R.J. 'Critical Thinking, Epistemic Virtue, and the Significance of Inclusion: Reflections on Harvey Siegel's Theory of Rationality', Educational Theory 54(3), 299-313. 
Kvanvig, J.L. (2003). The V alue of Knowledge and the Pursuit of Understanding. Cambridge: Cambridge University Press.

Kotzee, B. (Ed.) (2013). Education and the Growth of Knowledge: perspectives from social and virtue epistemology. Oxford: Wiley-Blackwell.

Kotzee, B. (2016). 'Learning How', Journal of Philosophy of Education 50 (2): 218 - 232.

Kraut, R. (1989). Aristotle on the Human Good. Princeton: Princeton University Press.

Louden, R. (1984). 'On Some Vices of Virtue Ethics' American Philosophical Quarterly 21(3), 227-36.

Macallister, J. (2012). 'Virtue Epistemology and the Philosophy of Education'. Journal of Philosophy of Education 46(2), 251-270.

Marples, R. (ed.) (1999). The Aims of Education. Routledge.

Montmarquet, J. (1993). Epistemic Virtue and Doxastic Responsibility. Rowman and Littlefield.

Olin, L and Doris, J.M. (2014). 'Vicious Minds'. Philosophical Studies 168(3), 665-692.

Porter, S. (2016). 'A Therapeutic Approach to Intellectual Virtue Formation in the Classroom' In:

Baehr, J. (ed) Intellectual Virtues and Education: Essays in Applied Virtue Epistemology. London: Routledge.

Pritchard, D. (2013). 'Epistemic Virtue and the Epistemology of Education'. Journal of Philosophy of Education 47(2), 236-247.

Ritchhart, R. (2002). Intellectual Character: What it Is, Why it Matters, and How to Get it. San Francisco: Jossey-Bass.

Riggs, Wayne D. (2003). 'Balancing our Epistemic Goals'. Noûs 37(2), 342-352.

Roberts, R. and Wood, J. (2007). Intellectual Virtues: An Essay in Regulative Epistemology. Oxford: Oxford University Press.

Scheffler, I. (1989). Reason and Teaching. Hackett Publishing.

Shah, N. (2003). 'How Truth Governs Belief'. Philosophical Review 112(4), 447-82.

Shah, N., and Velleman, J.D. (2005). 'Doxastic Deliberation'. Philosophical Review 114(4): 497-534.

Sher, G. (1998). 'Ethics, Character, and Action', Social Philosophy and Policy, 15(1), 1-17.

Sherman, N. (1989). The Fabric of Character: Aristotle's Theory of Virtue. Oxford University Press.

Siegel, H. (1988). 'Rationality and Epistemic Dependence, Educational Philosophy and Theory. 20(1): 1-6.

Siegel, H. (2013). Educating reason. Routledge.

Siegel, H. (1997). Rationality redeemed. Further dialogues on an educational ideal.

Siegel, H. (2017). 'Critical Thinking and the Intellectual Virtues', Intellectual Virtues and Education:

Essays in Applied Virtue Epistemology p. 95-112.

Siegel, H. (2018). Education's Epistemology: Rationality, Diversity, and Critical Thinking. Oxford: Oxford University Press.

Slote, M. (2001). Morals from Motives. Oxford University Press.

Solomon, D. (1988). 'Internal Objections to Virtue Ethics' Midwest Studies in Philosophy 13 (1):428441.

Sosa, E. (2010). Knowing Full Well. Princeton: Princeton University Press.

Sosa, E. (2009). A Virtue Epistemology: Apt Belief and Reflective Knowledge (Vol. 1). Oxford: Oxford University Press.

Sosa, E. (2015). Judgment and Agency. Oxford: Oxford University Press.

Sosa, E. (2017). Epistemology. Princeton: Princeton University Press.

Swanton, C. (2003). Virtue Ethics: A Pluralistic View. Oxford: Oxford University Press.

Tanesini, A. (2016). 'Teaching Virtue: Changing Attitudes'. Logos \& Episteme.

Turri, J. (2015). 'Epistemic Situationism and Cognitive Ability'. In Epistemic Situationism, edited by Alfano, Mark and Abrol Fairweather. Oxford University Press.

Tversky, A., and Kahneman, D. (1983). 'Extensional Versus Intuitive Reasoning: The Conjunction Fallacy in Probability Judgment', Psychological Review. 90, 4. 
Watson, L. (2015). 'Why should we Educate for Inquisitiveness?'. In Kotzee, B. (ed.), Intellectual Virtues and Education, Routledge, pp. 50-65.

Watson, L. (2016). 'The Epistemology of Education' Philosophy Compass, 11(3), 146-159.

Wedgwood, R. (2002). 'The Aim of Belief. Nous 36, 267-97.

Wolterstorff, N. (1996). John Locke and the Ethics of Belief. Cambridge University Press.

Zagzebski, L. (1996). Virtues of the Mind: An Inquiry into the Nature of Virtue and the Ethical Foundations of Knowledge. Cambridge: Cambridge University Press.

Zagzebski, L. (2017). Exemplarist Moral Theory. Oxford: Oxford University Press. 